Article

\title{
Fish is the Preferred Animal-Source Food in the Rural Community of Southern Bangladesh
}

\author{
Rumana Akter ${ }^{1}$, Shakuntala H. Thilsted ${ }^{2}$, Nazia Hossain ${ }^{3}\left(\mathbb{D}\right.$, Hiroe Ishihara ${ }^{1}$ and Nobuyuki Yagi ${ }^{1, *(D)}$ \\ 1 Graduate School of Agricultural and Life Sciences, The University of Tokyo, Room 533, Agriculture Building 7-B, \\ 1-1-1 Yayoi, Bunkyo-ku, Tokyo 113-0032, Japan; rumana87@hotmail.com (R.A.); a-hiroe@mail.ecc.u-tokyo.ac.jp (H.I.) \\ 2 WorldFish, Jalan Batu Maung, Batu Maung, 11960 Bayan Lepas, Penang, Malaysia; s.thilsted@cgiar.org \\ 3 Department of Zoology, University of Dhaka, Dhaka 1000, Bangladesh; nazia1hossain@gmail.com \\ * Correspondence: yagi@fs.a.u-tokyo.ac.jp; Tel.: +81-03-5841-5599
}

Received: 13 September 2019; Accepted: 15 October 2019; Published: 17 October 2019

check for updates

\begin{abstract}
Increased intake of animal-source foods (ASFs) is crucial to tackle multiple nutritional challenges in Bangladesh, and contribute to achieving targets under the Sustainable Development Goals (SDGs). Qualitative and quantitative data were collected to assess current ASFs intake behaviors and preferred ASFs, among three types of households, namely 1 . aquaculture intervention (AI); 2. aquaculture non-intervention (ANI); and 3. non-aquaculture non-intervention (NANI) households and children aged 6-59 months, to understand whether intake of ASFs vary by the types of households. Purposive sampling was conducted to obtain a total of 100 households (AI, 50; ANI, 25; NANI, 25). Fish was the most commonly consumed (52.2-61.5\%) and preferred (73.9-84.6\%) ASF by the majority households, across study groups; although amount (mean $\pm \mathrm{SD}$ ) of intake $(\mathrm{g} / \mathrm{d} /$ person) by NANI households was statistically significantly lower (NANI, $105.5 \pm 53.3 ; p<0.001$ ), compared to other two groups (AI, $163.6 \pm 64.7$ and ANI, $159.6 \pm 53$ ). Fish species selection for household consumption was led by taste, health benefits, availability, and price. Pangasius was the first fish species of choice fed to children, due to having fewer small bones compared to other commonly consumed fish species. Dietary interventions to prioritize fish, in targeting increased intake of ASFs among study population, for improved food and nutrition security.
\end{abstract}

Keywords: ASF; dietary intervention; preferred food; fish; drivers of food choice; malnutrition

\section{Introduction}

Despite a significant improvement in reducing hunger and food insecurity in Bangladesh, malnutrition (under- and over-nutrition) continues to remain a serious public health concern [1]; $35 \%$ of children under five years children are stunted (low height for age), and 35\% of adolescent girls and $16 \%$ of adult females have low body mass index (BMI) [2]. While there is a steady but slow decrease in under-nutrition among young children and women; a sharp continual increase in over-nutrition (overweight and obesity), is also seen among the same population [3,4]. In addition, multiple micronutrient (essential vitamins and minerals, for example, vitamin A, vitamin B12, folic acid, riboflavin, thiamin, niacin, calcium, iron, zinc, and iodine) deficiencies reported in Bangladesh, are highly prevalent especially among women of reproductive age (15-49 years), and pre-school and school-aged children [5-8]. Co-existence of these nutritional problems reflects a monotonous dietary pattern, high in energy but low in a variety of essential micronutrients [9-12]. Poor diet quality, which lacks diversity is associated with higher nutritional deficiencies, globally, and especially in low-income countries [13]. Young children and women are particularly vulnerable to this situation $[14,15]$. 
Inadequate intake of animal-source foods (ASFs) is one of the major factors responsible for the poor diet quality, nutrient inadequacy, and undernutrition among young children and women in Bangladesh, as reported by the Food and Agricultural Organization (FAO) and World Health Organization (WHO) $[16,17]$.

In Bangladesh, traditionally, the major part of the food plate is occupied by the staple food, rice [18]. The amounts of ASFs and other plant-source foods consumed are far below the recommended dietary guidelines of Bangladesh, as well as global standard [19,20]. Fish (mostly from aquaculture) is the most commonly consumed ASF in Bangladesh, compared to other ASFs, such as: meat (beef, lamb and mutton, sheep, goat, and pork) milk, egg, and chicken [21]; but the amount of per capita intake is minimal. Cultured fish has become more prominent in recent years, in Bangladesh; to compensate declining fish production from capture fisheries [22]. However, eating meat and chicken is occasional and festive. Regular intake of milk, milk products, and egg is also uncommon [23]. Various studies have reported that intake of ASFs is strongly associated with better growth, cognition, productivity, and pregnancy outcomes [14,24]. ASFs are not only rich sources of readily digestible high quality protein, but also rich sources of highly bioavailable nutrients of concern globally, such as iron, zinc, calcium, preformed vitamin A, vitamin B12, and folic acid [9]. For vitamin B12, ASFs are the only sources to meet the requirements $[9,14]$. Studies have shown that adding a small amount of ASF to a plant-based diet, can enhance the absorption of vitamins and minerals from these foods, and can significantly impact maternal health and child development $[9,12,13]$; although, certain ASFs such as red meat are subjected to debate, due to saturated fats and cholesterol.

Given the complex nutritional situation (prevalence of under- and over-nutrition in the same population, household, or individual level) in Bangladesh, and poor diet quality; increased intake of ASF is crucial for improved food and nutrition security. Therefore, this study aims to explore current behaviors of intake of ASFs, in three different groups of households and in children (aged 6-59 months), in a rural district of southern Bangladesh. The study further investigated what would be the preferred ASFs of the households, if the households had increased food purchasing capacity. To bring sustainable behavior change in ASFs intake, sustainable food system needs to be ensured, that is culturally acceptable and liked by the target people.

\section{Materials and Methods}

Qualitative and quantitative data were collected, using a semi-structured questionnaire in February 2018, in Barisal, a rural district in southern Bangladesh. Barisal district was selected to be able to include households, which had participated in a large-scale United States Agency for International Development (USAID) — funded project for five years. Using a purposive sampling method, three groups of households were selected, namely 1) aquaculture intervention (AI); 2) aquaculture non-intervention (ANI); and 3) non-aquaculture non-intervention (NANI) households, having at least one child, aged 6-59 months. A total of 100 households were selected for conducting the survey. This sample size was based on resources available for this survey. Half of the households (AI, $n=50)$ had participated in the USAID-funded AI project, conducting pond aquaculture either in their own ponds or leased ponds, with technical support on fish culture (mainly tilapia, mola carplet; carp species, and pangasius were also cultured) from the project; called intervention households. In addition, AI households also received nutrition education on the importance of eating and feeding diverse diets including fish to the children. The other half of the non-intervention households (ANI, $n=25$; and NANI, $n=25$ ), were not engaged in any kind of aquaculture projects, although ANI households were conducting pond aquaculture out of their own interest, and the NANI households were not involved in any kind of aquaculture activities. As fish is the most commonly consumed ASF reported by various studies in Bangladesh [18,25,26], 
these three different groups of households were selected purposively, to investigate if intake of fish and other ASFs vary by the type of households. For better comparison amongst the three study groups, all households selected had a similar socio-demography (housing condition (observational), current main occupation of the household head and educational level of the father and mother of the child). Consistent with the revised Helsinki Declaration in 1983, informed consent was obtained orally from all study participants, before interviews were conducted. Furthermore, the study was approved by the Ethics Review Committee of the University of Tokyo.

\subsection{Training and Data Collection}

Four Bengali speaking enumerators who had experience conducting similar household surveys were recruited. The enumerators received two days of intensive training on administering the semi-structured questionnaire, and practical training on conducting an interview. Pre-testing of the questionnaire was conducted and adjustments made. The semi-structured questionnaire captured both qualitative and quantitative information. Qualitative information includes: name of the most commonly consumed ASF and preferred ASFs; reasons of eating commonly consumed ASFs by the households and children (aged 6-59 months); name of the first given ASF to the child; name of the cultured fish species (AI and ANI); level of education of the mother or caregiver of the child and the father; current main occupation of the household head; and if there is any seasonality effect on the intake of ASFs by the households. Quantitative information includes: household size; age of children; estimated amount (grams/day) of the most commonly consumed ASF by the household; and number of days in a week the household eats the most commonly consumed ASF. Household and child level ASFs intake information were collected from the recall of the mother or caregiver of the child, responsible for preparing and serving foods to household members. Pre-testing of the questionnaire was conducted and adjustments made. Data were cross-checked for any inconsistency by the enumerators, on the same day of conducting the survey, after finishing the interview.

\subsection{Data Entry and Analysis}

Data were entered in Microsoft Excel and analyzed using the statistical software (Stata 15.1). Descriptive results are presented as mean $( \pm \mathrm{SD})$ and percentage $(\%)$. As sample size in each non-intervention group (ANI $=25$ and NANI $=25$ ) was half of that of the USAID-project intervention group $(\mathrm{AI}=50)$, Fisher's exact test was performed to see whether there was any statistical significant differences, in terms of the prevalence of the most commonly consumed ASF among study groups. The estimated amount of daily fish intake by the household, was divided by the number of household members, to obtain the amount of daily per capita fish intake, as suggested by FAO [27,28]. One-way analysis of variance (ANOVA) was performed, to see whether the quantity of daily per capita fish intake differed among three study groups. Tukey's post hoc test was conducted to confirm where the fish intake amount differed between groups. A $p$ value less than 0.05 was considered as statistically significant.

\section{Results}

\subsection{Basic Characteristics of the Study Households}

The current main occupation (Table 1) for most of the household heads was farming (AI 43.1\%; ANI 38.2\%; and NANI 41.9\%). More than half of the women respondents had received education up to the secondary level (AI 54.9\%; ANI 60.9\%; and NANI 50\%). About one-third of the women respondents had education up to the primary level (AI 31.4\%; ANI 30.4\%; and NANI 38.5\%). 
Table 1. Basic characteristics of the study households.

\begin{tabular}{lccc}
\hline & \multicolumn{1}{c}{ \% } \\
\cline { 2 - 4 } & AI, $\boldsymbol{n}=\mathbf{5 0}$ & ANI, $\boldsymbol{n}=\mathbf{2 5}$ & NANI, $\boldsymbol{n}=\mathbf{2 5}$ \\
\hline Current main occupation of household head & & & 41.9 \\
Farming & 43.1 & 38.2 & 15.4 \\
Self-employed a & 18.4 & 23.7 & 18 \\
Daily wage labor b & 15.6 & 14 & 19.1 \\
Production c & 16 & 17.6 & 4.7 \\
No earning & 4.9 & 3 & 0.9 \\
Salaried work d & 2 & 3.5 & 50 \\
Education level of women respondents & & & 38.5 \\
Up to secondary (up to grade 10) & 54.9 & 60.9 & 11.5 \\
Up to primary (up to grade 5) & 31.4 & 30.4 & 0 \\
College to graduate & 11.8 & 8.7 & $4.3 \pm 0.2$ \\
No education & 2.0 & 0 & \\
Household size (mean \pm SD) & $4.8 \pm 0.2$ & $5.3 \pm 0.2$ & \\
\hline
\end{tabular}

SD, standard deviation, ${ }^{a}$ tailor, potter, electrician; ${ }^{\mathrm{b}}$ agriculture day labor/earth work; ${ }^{\mathrm{c}}$ factory or garment worker; ${ }^{\mathrm{d}}$ teacher, NGO worker; AI, aquaculture intervention households; ANI, aquaculture non-intervention households; NANI, non-aquaculture non-intervention households.

\subsection{Commonly Consumed ASFs by the Households}

Fish was the most commonly consumed ASF compared to other ASFs, reported by the majority of NANI households (61.5\%; Figure 1). Similar responses were given by the other two groups (AI 53\% and ANI 52.2\%); and the differences in fish intake prevalence among three different groups were not statistically significant $(p>0.05)$, confirmed by the Fisher's exact test.

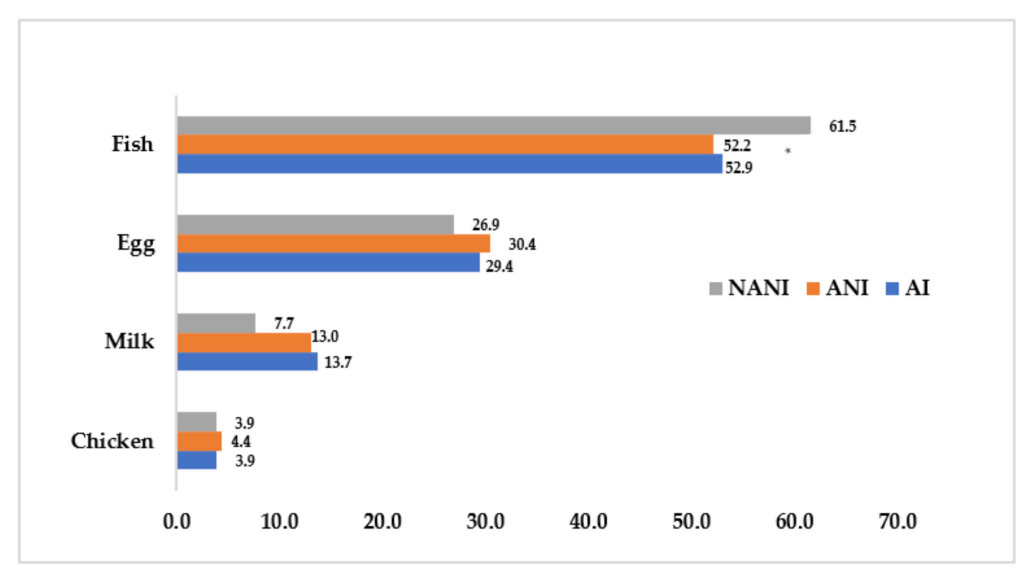

Figure 1. Most commonly consumed animal-source food (ASF) by the households (\%). ${ }^{*} p>0.05$, using the Fisher's exact test; AI, aquaculture intervention households; ANI, aquaculture non-intervention households; NANI, non-aquaculture non-intervention households; ASF, animal-source food.

However, the one-way ANOVA (Table 2) shows that daily average per capita fish intake quantity, was statistically significantly different $(\mathrm{F}(2.97)=8.6, p<0.001)$, among study groups. Quantity of daily per capita fish intake (mean \pm SD) reported by NANI households was much lower (105.5 \pm 53 ) of that of the other two groups (AI, $163.6 \pm 64.7$; and ANI, $159.6 \pm 53$ ). Tukey's post-hoc test confirmed that there was statistically significantly $(p<0.001)$ lower fish intake quantity (person/day) among the NANI households compared to AI and ANI households (Table 3). 
Table 2. One-way ANOVA showing daily average per capita fish intake quantity $(n=100)$.

\begin{tabular}{cccccc}
\hline & Mean (g/d/Person) & SD & df & F & $p$ \\
\hline AI & 163.6 & 64.7 & 99 & 8.6 & $<0.001$ \\
ANI & 159.6 & 57.5 & & & \\
NANI & 105.5 & 53.0 & & & \\
\hline
\end{tabular}

df, degrees of freedom; SD, standard deviation; AI, aquaculture intervention household; ANI, aquaculture non-intervention household; NANI, non-aquaculture non-intervention household.

Table 3. Pairwise comparisons of means with equal variances (Tukey post-hoc test).

\begin{tabular}{cccccc}
\hline & & & \multicolumn{3}{c}{ Tukey } \\
\cline { 4 - 6 } & Contrast & SE & $\mathbf{t}$ & Sig & $\mathbf{9 5 \% ~ C I ~}$ \\
\hline ANI vs. AI & -4.0 & 15.1 & -0.3 & 0.963 & -40.0 to 32.1 \\
NANI vs. AI & -58.1 & 14.5 & -4.0 & $<0.001$ & -92.7 to -23.5 \\
NANI vs. ANI & -54.1 & 17.3 & -3.1 & 0.006 & -95.2 to -13.1 \\
\hline
\end{tabular}

$\mathrm{AI}$, aquaculture intervention households; $\mathrm{ANI}$, aquaculture, non-intervention households; NANI, non-aquaculture non-intervention households; SE, standard error; Sig, significance/ $p$-value; CI, confidence interval.

\subsection{Preferred Animal-Source Foods by the Study Households}

Fish (mostly from aquaculture) is not only the most commonly consumed ASF (from Figure 1), but is also the preferred ASF, reported by the majority households from all study groups (Figure 2). More than three-quarter of the respondents $(84.6 \%)$ from NANI households reported fish as the preferred ASF (Figure 2). Similar responses were given by AI (76.5\%) and ANI households (73.9\%). More than two-quarters of NANI households (69.2\%) also reported chicken as the preferred ASF. Similarly, more than two-quarter of AI households (68\%) also reported egg as the preferred ASF, followed by milk (56.9\%). Furthermore, more than half of ANI households (56.5\%) also reported chicken and egg as preferred foods too.

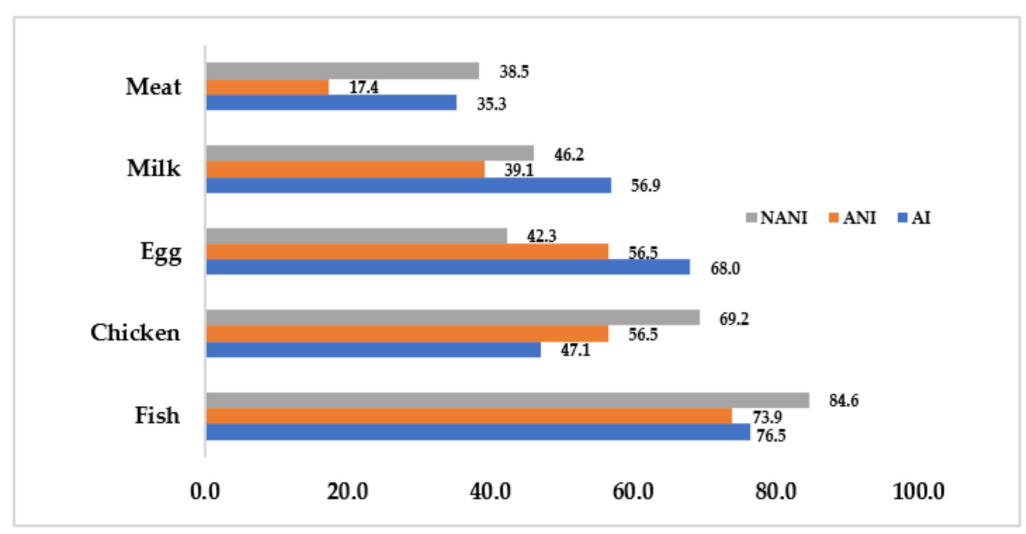

Figure 2. Preferred ASFs of study households (multiple responses, \%). AI, aquaculture intervention household; ANI, aquaculture non-intervention household; NANI, non-aquaculture non-intervention household; ASF, animal-source food.

\subsection{Commonly Consumed Fish Species by Study Households}

Almost all AI households reported eating tilapia (98\%) most frequently, followed by mola carplet (92\%) and carp species (86.3\%; Figure 3). Whereas the majority of the ANI households (95.7\%) reported eating pangasius and carp species, followed by tilapia (91.3\%), and mola carplet (78.3\%). In contrast, juvenile hilsa (from wild catch) was the most commonly consumed fish reported by the majority of NANI households $(88.5 \%)$, followed by tilapia $(84.6 \%)$, and pangasius and carp species $(80.8 \%)$. 


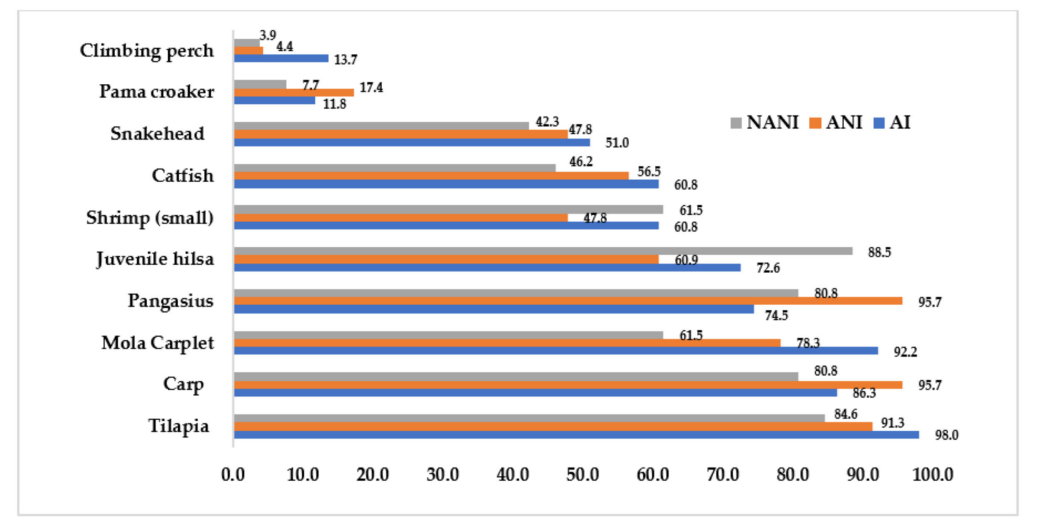

Figure 3. Commonly consumed fish species by study households (multiple responses, \%). AI, aquaculture intervention household; ANI, aquaculture non-intervention household; NANI, non-aquaculture non-intervention household.

\subsection{Reasons for Consumption of Common Fish Species by Study Households}

The majority of households (Figure 4) in all three groups (78.3-92.3\%) gave the reason for eating these fish species as: "like the taste". Almost all NANI households (96.2\%) said that fish is "good for health", followed by AI households (86.3\%). The reason for eating these species was due to availability from "own production", mentioned by about three-quarters (72.6\%) of AI and half of ANI (52.2\%) households. About one-fourth (21.7-30.8\%) of households from all groups mentioned "low price" as the reason for eating these fish species.

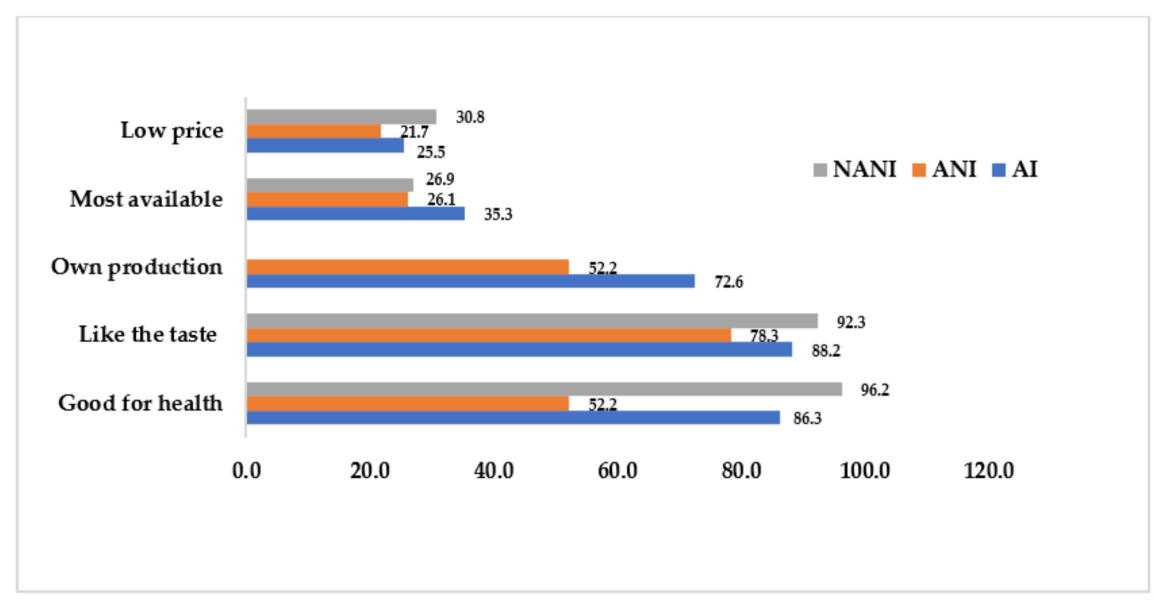

Figure 4. Reasons for consumption of common fish species by study households (multiple responses, \%). AI, aquaculture intervention household; ANI, aquaculture non-intervention household; NANI, non-aquaculture non-intervention household.

\subsection{Preferred Fish Species by Study Households}

Hilsa was the preferred fish species (Figure 5), reported by the majority of households from all groups (AI 88.2\%; ANI 87.0\%; and NANI 80.8\%); followed by large shrimp (ANI 69.6\%; NANI 69.2\%; and AI 68.6\%) and walking catfish (NANI 65.4\%; AI 56.9\%; and ANI 56.5\%). Interestingly, almost none of the AI and ANI households mentioned tilapia as their preferred fish species, whereas, it was the most commonly consumed fish by the majority of households (Figure 3). 


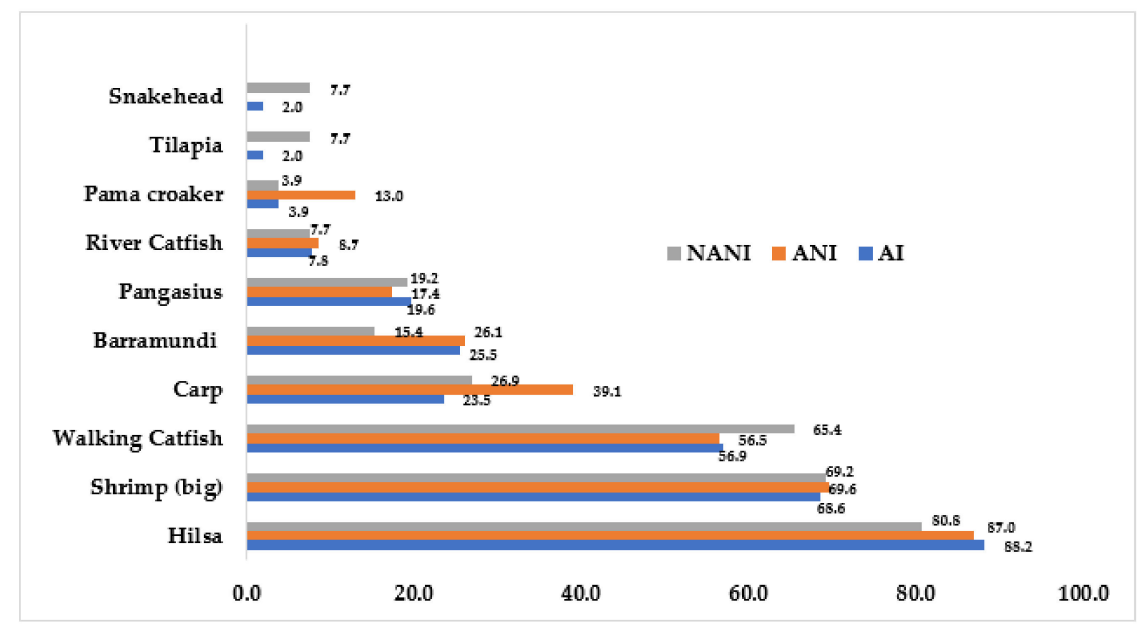

Figure 5. Preferred fish species by study households (multiple responses, \%). AI, aquaculture intervention household; ANI, aquaculture non-intervention household; NANI, non-aquaculture non-intervention household.

The reasons for liking these species were "very delicious" and "rarely found" mentioned by most of the respondents of all three groups (data not shown). On average, households from all groups reported eating fish three to five days in a week. Furthermore, household level fish consumption was reported to be influenced by seasonality. A larger quantity and diverse fish species were eaten in the peak fishing season (July to November) due to high availability in the market from wild catch and also low price.

\subsection{Fish Species that was First Fed to the Child}

Almost all respondents from all three groups, reported feeding fish to their young children, aged 6-59 months (data not shown). Pangasius was reported as the first fish species, fed to the child (Figure 6), by the majority of respondents (62.5\%) from NANI households, followed by ANI ( $45.5 \%)$ and AI (36\%). Mola carplet was mentioned as the first fish species, fed to many children (14\%) of AI households.

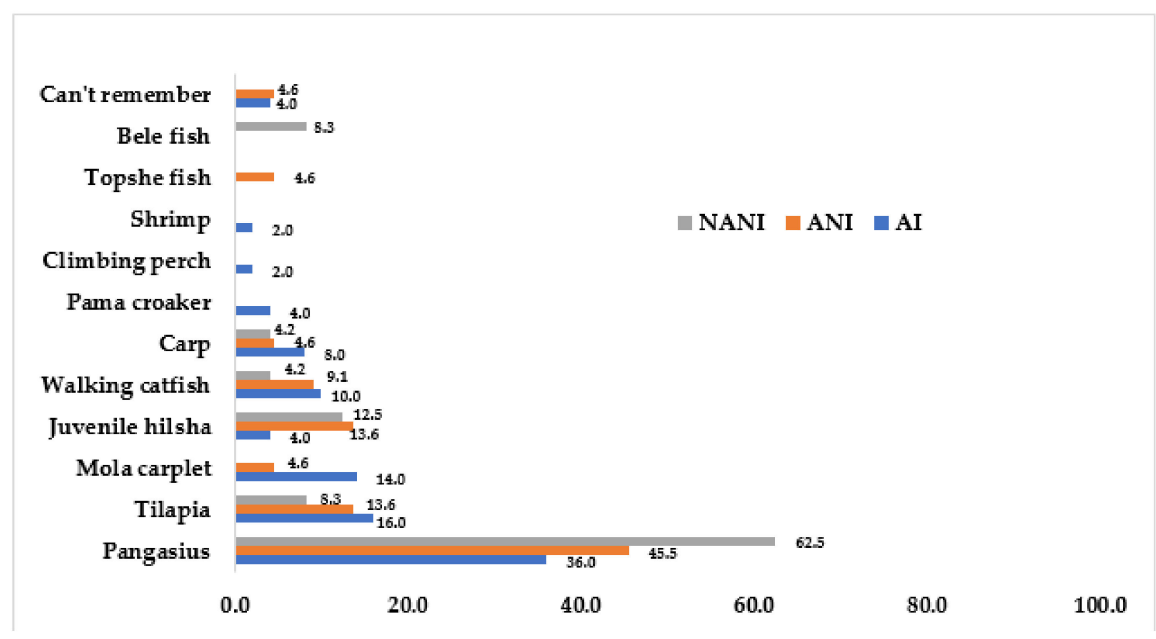

Figure 6. Fish species that was first fed to the child (\%). AI, aquaculture intervention household; ANI, aquaculture non-intervention household; NANI, non-aquaculture non-intervention household. 


\subsection{Reasons for Choosing the Fish Species to be First Given to the Child}

One of the important reasons for giving pangasius to children was "fewer bones" (Figure 7), mentioned by the majority of the respondents from all three groups (75-78\%), followed by "nutritious" (AI 76\%; NANI 66.7\%; and ANI 45.5\%). About one-third (32\%) of respondents from AI households reported, the reasons for feeding fish to the child were: "most available" and "own production". "low price" of fish was also reported by NANI households (16.7\%) for fish species chosen to be fed to children.

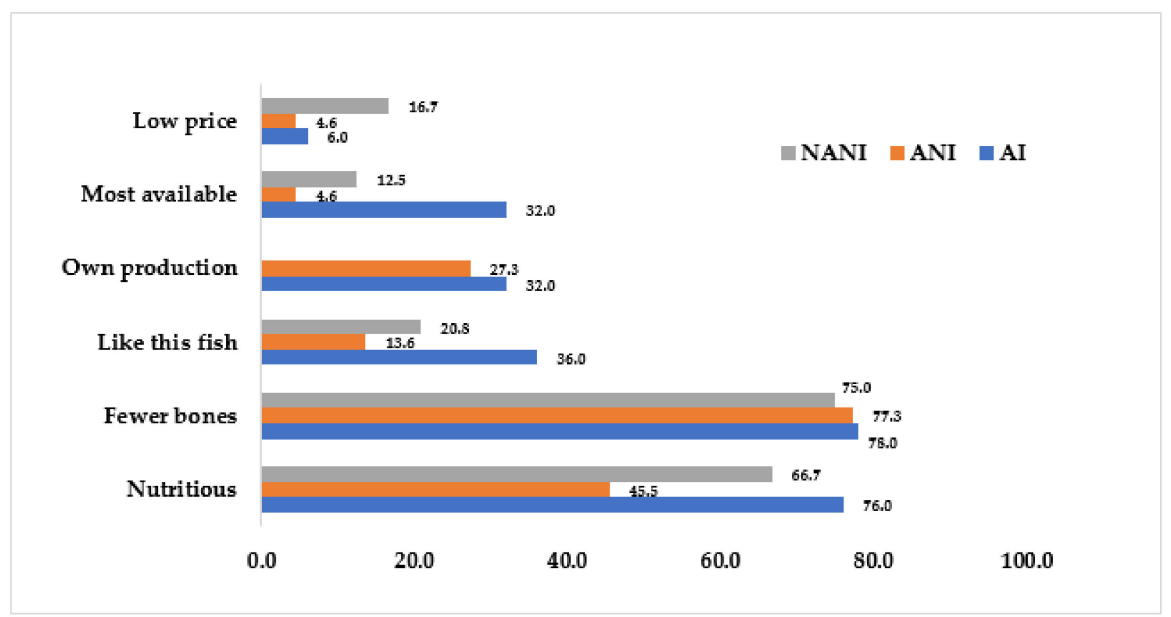

Figure 7. Reasons for choosing fish species to be first given to the child (multiple responses, \%). AI, aquaculture intervention households; ANI, aquaculture non-intervention households; NANI, non-aquaculture non-intervention households.

\section{Discussion}

Fish is the most commonly consumed ASF reported by households in all three study groups (Figure 1). This finding is consistent with many other studies in Bangladesh [18,21,29]. Fish was also the preferred ASF reported by the majority of households in all study groups (Figure 2). These results further reinforce the importance of fish in the diet of the study population. Fish is the second most valuable agricultural food crop in Bangladesh, after rice [30]. Traditionally, people eat fish, irrespective of region, ethnicity, income, or education category. The species selected for consumption can vary, depending on the purchasing capacity of the household or an individual and the availability of fish species, as reflected in this study (Figures 4 and 7). Fish has a special places in the Bengali diet, with people celebrating traditional festivals (e.g., Bengali New Year, and a wedding), by eating and gifting fish to each other (family, friends, and relatives). Chicken, egg, and milk were also preferred ASFs, as reported by the many households from all three groups; however, the prevalence of intake of these ASFs (chicken, egg, and milk), at the national level are quite low $(22 \%, 21 \%$, and $23.2 \%$, respectively) [18,31]. Furthermore, eating chicken and meat (beef, goat, lamb and mutton, and pork) are occasional and festive; and regular intake of egg and milk is uncommon. In addition, intake of multiple ASFs in a single day is rare in Bangladesh [21].

Tilapia, and mola carplet were the most commonly consumed fish species by the AI households, perhaps due to these households producing these species as a part of the aquaculture intervention project. Therefore, they were the most convenient and accessible species and did not have to be purchased (Figure 3). This finding is consistent with studies, showing that people tend to eat the food they produce and is available at home [32,33]. Intake of mola carplet was particularly higher among AI households, compared to the other two groups. This is important to note that the AI households received nutrition education on the importance of fish consumption, especially small indigenous fish such as mola carplet, as these species are rich sources of multiple micronutrients, especially vitamin A, vitamin B 12, folic acid, calcium, iron, and zinc; which are mostly deficient in 
the Bangladeshi population [5,26,34-36]. Therefore, it is assumed that along with availability and accessibility, nutrition education might have also influenced AI households, to consume the fish species produced in their ponds. This kind of fish consumption behavior indicates the importance of the food environment and the necessity of health promotion activities, to promote intake of specific target foods [37,38]. In Bangladesh, the most cultivated fish species are: carp species, tilapia, pangasius, and in some cases mola carplet; due to the availability of proven production technologies and these species are more resilient to the environment $[21,22,39]$. Therefore, consumption of carp species, pangasius, and tilapia by the majority of households from all study groups is not surprising. Furthermore, close proximity to AI households may have indirectly influenced ANI and NANI households, to consume these cultured fish species through market access and nutrition information. Moreover, there have been nationwide campaigns on eating mola carplet, due to its high nutritional quality (mola carplet is a rich source of vitamin A, which is highly deficient among Bangladeshi people [5]). Therefore, consumption of mola carplet by many ANI and NANI households is also not surprising. Furthermore, the reason for eating juvenile hilsa (from wild catch) by the majority of NANI households (Figure 3) may be due to its low price, compared to other fish species; which was also reflected by the responses of one-third of NANI households; "low price" was the reason of eating commonly consumed fish species (Figure 4).

The estimated amount of daily per capita fish intake in all three groups was lower compared to the recommended intake quantity of ASFs $[19,20]$. Daily per capita fish intake quantity was further lower among NANI households (Table 3), compared to the two other groups of households (AI and ANI), and the differences in intake quantity were statistically significantly lower $(p<0.01)$, among NANI households (Table 2). A combination of availability and accessibility of fish at the household level from their own production might have influenced the higher quantity of fish intake in AI and ANI households, compared to NANI households. These findings are also reflected by the responses of AI and ANI households; the majority of the respondents reported availability from their "own production" as the reason for eating these fish species (Figure 4). Nonetheless, alike many other studies in Bangladesh, this study also found that respondents across all study groups "like the taste" of fish $[25,30,40]$. "good for health" or "nutritious" was an important reason for eating and feeding children fish, mentioned by respondents in all study groups.

It is interesting that hilsa was named as the preferred fish by the majority of households from all three study groups, if households had sufficient money to buy foods (Figure 5). In Bangladesh, hilsa is the national fish, considered special and eaten at the Bengali New Year. Traditionally, people like hilsa due to its taste, texture, and flavor. The cost of an adult hilsa (about $1 \mathrm{~kg}$ ) is high compared to other fish species and mostly not affordable by rural households. Large shrimp and walking catfish are also expensive compared to commonly consumed fish species. Therefore, naming these fish species as preferred fish by all study groups is not surprising; as these fish species are mostly beyond their reach and they aspire to eat them.

Most of the respondents from all three groups mentioned of feeding pangasius to their child as the first fish species (Figure 6), due to this fish having fewer small bones compared to other commonly consumed fish species (Figure 3). This finding is consistent with another study in Bangladesh, in the same area [41]; mothers reported not feeding all fish species to their children that they ate themselves, due to the fear of bones. Mola carplet was given to more children in AI households than ANI, which might be due to the availability of this fish from their own production due to the project intervention, as well as nutrition education provided by the project. This result indicates that if households or individuals can be communicated about the health and nutritional benefits of a culturally acceptable and affordable food; it is likely that this food will be consumed [39].

Results of this study as well as the literature review show the importance of fish in the diet of the Bangladeshi people, which is consistent with the traditional proverb "Mache bhate Bangali" meaning "fish and rice make a Bengali"; although species selection is guided by various factors, such as: food environment, affordability, social norm, and context (e.g., age, and seasonality). One of the objectives of nutrition-sensitive interventions is, to make micronutrient-rich foods available and accessible, so that 
the household can readily consume these foods, either from own production or nearby market [42]. This pathway is supported by the study results from the AI and ANI households, having a greater household level consumption than the NANI households [43]. As "low price" of fish was one of the important reasons for eating fish, mentioned by many respondents from all groups (Figure 4), it was assumed that if people had increased food purchasing capacity; they would shift their food choice from fish to other ASFs. The results from this study does not support this; the respondents reported that they would eat fish if they had enough food purchasing capacity; however, their choice of species would be different (Figure 5). They would want to eat more delicious, expensive, and rare fish species. Therefore, increased purchasing capacity along with production diversity might create an enabling food environment, for households and individuals to eat a larger quantity of fish and more diversified fish species, thus improving diet quality [44,45].

Food availability at the global, national, or sub-national level does not guarantee food and nutrition security at the community or households level [46,47]. Access to food (physical and economic access) by households or individuals plays a vital role for the food choice of people [48], which is also reflected by the results of this study. This study further reveals that personal food preferences are determined by various factors, such as: availability, convenience, taste, value, culture, knowledge, and age [46,49]. These results are aligned with the food choice process model of Cornel University [49], which shows that food preferences of an individual is influenced by the life course events and experiences (early life exposure and upbringing), including current factors, such as: context, accessibility, health condition, convenience, and taste. The personal food choice of an individual is a cognitive process and early family cuisine and food preferences provide food roots of people that people carry over time [50,51]. Therefore, dietary interventions need to prioritize cultural acceptability and food preferences, when deciding on intervention components. This study provides useful information regarding current ASFs intake behaviors, and preferred ASFs of households in a rural district of southern Bangladesh.

\section{Conclusions}

Fish is the most commonly consumed and preferred ASF, across study groups. People were more likely to consume the fish species that was available from their own production. Selection of fish species for consumption was led by the taste, health benefits, or nutrition knowledge of household members, availability in the market, price, and age of child. Daily per capita amount of fish intake was lower in households (NANI) did not produce fish, compared to households (AI and ANI) produced fish. In feeding fish to children (aged 6-59 months), fish species with fewer small bones were the species of choice. Therefore, this study suggests dietary interventions to consider the age of child, when choosing specific micronutrient-rich food to promote, for improved food and nutrition security. Considering the malnutrition situation in Bangladesh and the cultural acceptability and preferences of fish, this study recommends that dietary interventions to prioritize fish in targeting increased intake of ASFs for improved nutrition. This effort will contribute to achieving targets under the Sustainable Development Goals (SDGs), through reducing malnutrition, child mortality, and improving school attainment of children.

Limitations of the study: The study was conducted in one rural district in southern Bangladesh and therefore, the findings do not represent the country as a whole.

Author Contributions: R.A. designed the survey and conceptualized, analyzed and prepared the original draft; N.Y. guided the overall survey design and reviewed the questionnaire; N.H. carried out data collection and data entry; H.I. gave inputs on the food choice process model; R.A. interpreted the results; S.H.T.; H.I., and N.Y. reviewed, edited and contributed to formulating the manuscript.

Funding: Funding for conducting the survey was provided by the Japan Society for the Promotion of Science (JSPS, Grant number: 16H02565). 
Acknowledgments: We acknowledge Mostafa Hossain, Bangladesh Agricultural University, for his support during the survey and Hiroaki Sugino, The University of Tokyo, for his inputs in data set. The authors are grateful for the financial support provided by the JSPS. The authors would like to acknowledge Zakir Hossain and Zamal Uddin; WorldFish, Bangladesh; for their support during data collection. We are grateful to the anonymous reviewers for their valuable comments and suggestions.

Conflicts of Interest: The authors declare no conflict of interests.

\section{References}

1. Ahmed, T.; Mahfuz, M.; Ireen, S.; Shamsir Ahmed, A.M.; Rahman, S.; Munirul Islam, M.; Alam, N.; Iqbal Hossain, M.; Mustafizur Rahman, S.M.; Mohsin Ali, M.; et al. Nutrition of children and women in Bangladesh: Trends and directions for the future. J. Heal. Popul. Nutr. 2012, 30, 1. [CrossRef] [PubMed]

2. Osmani, S.R.; Ahmed, T.; Hossain, N.; Huq, S. Strategic Review of Food Security and Nutrition in Bangladesh; World Food Programme: Dhaka, Bangladesh, 2016.

3. Khan, S.H.; Talukder, S.H. Nutrition transition in Bangladesh: Is the country ready for this double burden. Obes. Rev. 2013, 14, 126-133. [CrossRef] [PubMed]

4. Hasan, M.; Sutradhar, I.; Shahabuddin, A.; Sarker, M. Double Burden of Malnutrition among Bangladeshi Women: A Literature Review. Cureus 2017, 12. [CrossRef] [PubMed]

5. ICDDRB; UNICEF; GAIN; IPHN. National Micronutrients Status Survey 2011-12; ICDDRB and UNICEF: Dhaka, Bangladesh, 2013.

6. Hernandez, R.; Belton, B.; Reardon, T.; Hu, C.; Zhang, X.; Ahmed, A. The "quiet revolution" in the aquaculture value chain in Bangladesh. Aquaculture 2018, 493, 456-468. [CrossRef]

7. Food And Agriculture Organization. Food Balance Sheets. Available online: http://www.fao.org/faostat/en/ \#data/FBS (accessed on 15 January 2018).

8. Bogard, J.R.; Farook, S.; Marks, G.C.; Waid, J.; Belton, B.; Ali, M.; Toufique, K.; Mamun, A.; Thilsted, S.H. Higher fish but lower micronutrient intakes: Temporal changes in fish consumption from capture fisheries and aquaculture in Bangladesh. PLoS ONE 2017, 12. [CrossRef]

9. Schönfeldt, H.C.; Pretorius, B.; Hall, N. The impact of animal source food products on human nutrition and health Under-nutrition in South Africa. S. Afr. J. Anim. Sci. 2013, 43, 394-412. [CrossRef]

10. Arsenault, J.E.; Yakes, E.A.; Islam, M.M.; Hossain, M.B.; Ahmed, T.; Hotz, C.; Lewis, B.; Rahman, A.S.; Jamil, K.M.; Brown, K.H. Very low adequacy of micronutrient intakes by young children and women in rural Bangladesh is primarily explained by low food intake and limited diversity. J. Nutr. 2013, 143, 197-203. [CrossRef]

11. Ahmed, F.; Prendiville, N.; Narayan, A. Micronutrient deficiencies among children and women in Bangladesh: Progress and challenges. J. Nutr. Sci. 2016, 5. [CrossRef]

12. Zhang, Z.; Goldsmith, D.P.; Winter-nelson, A. The Importance of Animal Source Foods for Nutrient Sufficiency in the Developing World: The Zambia Scenario. Food Nutr. Bull. 2016, 37, 303-316. [CrossRef]

13. Neumann, C.G.; Bwibo, N.O.; Murphy, S.P.; Sigman, M.; Whaley, S.; Allen, L.H.; Guthrie, D.; Weiss, E.; Demment, M.W. Animal Source Foods Improve Dietary Quality, Micronutrient Status, Growth and Cognitive Function in Kenyan School Children: Background, Study Design and Bas. J. Nutr. 2003, 3941-3949. [CrossRef]

14. Murphy, S.P.; Allen, L.H. Nutritional Importance of Animal Source Foods. J. Nutr 2003, 3932-3935. [CrossRef] [PubMed]

15. ACC/SCN. Fourth Report on The World Nutrition Situation: Nutrition throughout the Life Cycle; The UN system's forum for nutrition and IFPRI: Geneva, Switzerland, 2000.

16. FAO/WHO. Bangladesh Country Paper-Second International Conference on Nutrition (ICN2); FAO \& WHO: Rome, Italy, 2014.

17. Headey, D.D.; Hirvonen, K.; Hoddinott, J.F. Animal Sourced Foods and Child Stunting. IFPRI Discussion Paper 1695; IFPRI: Washington, DC, USA, 2017.

18. Bangladesh Bureau of Statistics (BBS). Preliminary Report on Household Income and Expenditure Survey 2016; Government of the People's Republic of Bangladesh: Dhaka, Bangladesh, 2017.

19. Loken, B.; Springmann, M.; DeClerck, F.; Wood, A.; Jonell, M.; Clark, M.; Gordon, J.L.; De Vries, W.; Afshin, A.; Chaudhary, A.; et al. Healthy Diets From Sustainable Food Systems. Food Planet Health; The EAT-Lancet Commossion: Stockholm, Sweden, 2019. 
20. Nahar, Q.; Choudhury, S.; Faruque, M.O.; Sultana, S.S.S.; Siddiquee, M.A. Dietary Guidelines for Bangladesh; Bangladesh Institute of Research and Rehabilatation in Diabetes, Endocrine, and Metabolic Disorders (BIRDEM): Dhaka, Bangladesh, 2013.

21. Belton, B.; Karim, M.; Thilsted, S.; Collis, W.; Phillips, M. Review of Aquaculture E Fish. Consumption in Bangladesh Review of Aquaculture and Fish. Consumption in Bangladesh; WorldFish: Dhaka, Bangladesh, 2011.

22. Sarker, S.; Basak, S.C.; Hasan, J.; Hossain, M.S.; Rahman, M.M.; Ahsanul Islam, M. Production in Small Scale Aquaculture Farm: A Success Story from Bangladesh. J. Aquac. Res. Dev. 2017, 8, 2. [CrossRef]

23. Copenhagen Consensus Center and CRi. Dietary Diversification in Bangladesh; Copenhagen Consensus Center: Copenhagen, Denmark, 2016.

24. Neumann, C.; Harris, D.M.; Rogers, L.M. Contribution of animal source foods in improving diet quality and function in children in the developing world. Nutr. Res. 2002, 22, 193-220. [CrossRef]

25. Belton, B.; Thilsted, S.H. Fisheries in transition: Food and nutrition security implications for the global South. Glob. Food Sec. 2014, 3, 59-66. [CrossRef]

26. Roos, N.; Islam, M.M.; Thilsted, S.H. Small Indigenous Fish Species in Bangladesh: Contribution to Vitamin A, Calcium and Iron Intakes. J. Nutr. 2003, 133, 4021S-4026S. [CrossRef] [PubMed]

27. FAO. Compendium of Indicators for Nutrition-Sensitive Agriculture; FAO and European Commission: Rome, Italy, 2016.

28. FAO. Dietary Assessment: A Resource Guide to Method Selection and Application in Low Resource Settings; FAO: Rome, Italy, 2018.

29. Waid, J.L.; Ali, M.; Thilsted, S.H.; Gabrysch, S. Dietary change in Bangladesh from 1985 to 2010. Glob. Food Sec. 2018, 17, 221-232. [CrossRef]

30. WorldFish. Brief: Aquaculture and Fish Consumption in Bangladesh; WorldFish: Dhaka, Bangladesh, 2011.

31. James P Grant School of Public Health and National Nutrition Services. State of Food Security and Nutrition in Bangladesh 2015; BRAC University: Dhaka, Bangladesh, 2016.

32. Fidalgo Castro, A. An Approach to the Food Habits of Three Communities in Timor-Leste; CARE International: Dili, Timor-Leste, 2013.

33. Stellmacher, T.; Kelboro, G. Family Farms, Agricultural Productivity, and the Terrain of Food (In)security in Ethiopia. Sustainability 2019, 11, 4981. [CrossRef]

34. Bogard, J.R.; Thilsted, S.H.; Marks, G.C.; Wahab, M.A.; Hossain, M.A.R.; Jakobsen, J.; Stangoulis, J. Nutrient composition of important fish species in Bangladesh and potential contribution to recommended nutrient intakes. J. Food Compos. Anal. 2015, 42, 120-133. [CrossRef]

35. Shaheen, N.; MA Rahim, A.T.; Mohiduzzaman, M.; Banu, P.C.; Bari, M.L.; Tukun, B.A.; Mannan, M.; Bhattacharjee, L.; Stadlmayr, B. Food Composition Table for Bangladesh, 1st ed.; Institute of Nutrition and Food Science, Center for Advanced Research and in Sciences: Dhaka, Bangladesh, 2014.

36. Coldebella, A.; Gentelini, A.L.; Piana, P.A.; Coldebella, P.F.; Boscolo, W.R.; Feiden, A. Effluents from fish farming ponds: A view from the perspective of its main components. Sustainability 2018, 10, 3. [CrossRef]

37. Herforth, A.; Ahmed, S. The food environment, its effects on dietary consumption, and potential for measurement within agriculture-nutrition interventions. Food Sec. 2015, 7, 505-520. [CrossRef]

38. Odunitan-Wayas, F.; Okop, K.; Dover, R.; Alaba, O.; Micklesfield, L.; Puoane, T.; Uys, M.; Tsolekile, L.; Levitt, N.; Battersby, J.; et al. Food purchasing characteristics and perceptions of neighborhood food environment of South Africans living in low-, middle- and high-socioeconomic neighborhoods. Sustainability 2018, 10, 4801. [CrossRef]

39. Castine, S.A.; Bogard, J.R.; Barman, B.K.; Karim, M.; Mokarrom Hossain, M.; Kunda, M.; Mahfuzul Haque, A.B.M.; Phillips, M.J.; Thilsted, S.H. Homestead pond polyculture can improve access to nutritious small fish. Food Secur. 2017, 9, 785-801. [CrossRef]

40. Roos, N.; Wahab, M.A.; Chamnan, C.; Thilsted, S.H. The Role of Fish in Food-Based Strategies to Combat Vitamin A and Mineral Deficiencies in Developing Countries. J. Nutr. 2007, 137, 1106-1109. [CrossRef] [PubMed]

41. Thorne-Lyman, A.L.; Valpiani, N.; Akter, R.; Baten, M.A.; Genschick, S.; Karim, M.; Thilsted, S.H. Fish and Meat Are Often Withheld From the Diets of Infants 6 to 12 Months in Fish-Farming Households in Rural Bangladesh. Food Nutr. Bull. 2017, 38, 354-368. [CrossRef]

42. The World Bank. From Agriculture to Nutrition Pathways, Synergies, and Outcomes; The World Bank Agriculture and Rural Development Department: Washington, DC, USA, 2017. 
43. Akuffo, A.S.; Quagrainie, K.K. Assessment of household food security in fish farming communities in Ghana. Sustainability 2019, 11, 2807. [CrossRef]

44. FAO and FHI 360. Minimum Dietary Diversity for Women-A Guide to Measurement; FAO and FHI 360: Rome, Italy, 2016.

45. Sibhatu, K.T.; Krishna, V.V.; Qaim, M. Production diversity and dietary diversity in smallholder farm households. Proc. Natl. Acad. Sci. USA 2015, 112, 10657-10662. [CrossRef]

46. HLPE. Nutrition and Food Systems. A Report by the High Level Panel of Experts on Food Security and Nutrition of the Committee on World Food Security; CFS and HLPE: Rome, Italy, 2017.

47. Haysom, G.; Olsson, E.G.A.; Dymitrow, M.; Opiyo, P.; Taylor Buck, N.; Oloko, M.; Spring, C.; Fermskog, K.; Ingelhag, K.; Kotze, S.; et al. Food Systems Sustainability: An Examination of Different Viewpoints on Food System Change. Sustainability 2019, 11, 3337. [CrossRef]

48. Duran, A.C.; De Almeida, S.L.; Do, R.; Jaime, P.C. The role of the local retail food environment in fruit, vegetable and sugar-sweetened beverage consumption in Brazil. Public Health Nutr. 2015, 19, 1093-1102. [CrossRef]

49. Sobal, J.; Bisogni, C.A. Constructing food choice decisions. Ann. Behav. Med. 2009, 38 (Suppl. 1), s37-s46. [CrossRef]

50. Furst, T.; Connors, M.; Bisogni, C.A.; Sobal, J.; Falk, L.W. Food choice: A conceptual model of the process. Appetite 1996, 26, 247-266. [CrossRef]

51. Devine, C.M.; Connors, M.; Bisogni, C.A.; Sobal, J. Life-course influences on fruit and vegetable trajectories: Qualitative analysis of food choices. J. Nutr. Educ. Behav. 1998, 30, 361-370. [CrossRef]

(C) 2019 by the authors. Licensee MDPI, Basel, Switzerland. This article is an open access article distributed under the terms and conditions of the Creative Commons Attribution (CC BY) license (http://creativecommons.org/licenses/by/4.0/). 